\title{
Discussion on Reform of Preschool Pedagogy Course
}

\author{
Bianling Zhang \\ Huanghe Science and Technology College \\ Zhengzhou, China
}

\begin{abstract}
The reform of practice-based preschool pedagogy course shall be done from three aspects: first, make sure of the course goal and optimize course contents; second, strengthen the practice training in teaching and change class teaching modes; third, attach great importance to the practical evaluation and innovate examination methods.
\end{abstract}

Keywords—preschool pedagogy; course reform; practice-based

\section{INTRODUCTION}

Preschool pedagogy is a basic theory course for preschool education, required for the specialty. Originally, the preschool pedagogy is a subject of high practice, which is concerned about the real, rich and diverse educational life. ${ }^{[1]}$ In recent years, with the transformation of infant schools, there are more and more textbooks different in edition but similar in the system, whose contents are outdated, poor for practice and difficult to meet the requirements for reforms of early childhood education. "Focusing on theories and neglecting practices" can be widely seen in teaching modes and methods, due to the restriction in teaching times and some conditions, though some practical activities are arranged in some schools, yet it still gives an overall feeling that seems more in listening less in watching, more in writing but little in doing. This kind of teaching model ignores the significance to cultivate students' abilities, turning the teaching into a narrow, isolated and one-way activity. The reform of preschool pedagogy course should be based on practice and try to cultivate students' quality in education and childcare.

\section{MAKe Sure of Course GoAl AND OPtimize Course CONTENTS}

Course goals, core of the whole course, determine the course directions, contents and implementation processes. ${ }^{[1]}$ Considering the nature of subject and characteristics of students reading for preschool education, we have stressed that the goals of preschool education should be embodied in the two points as follows, first, we should cultivate and improve students' professional quality and enable them to grasp the philosophy of modern early childhood education in order for a scientific education; second, we should train and improve students' capabilities including those in environmental arrangement and use, communication and cooperation with parents, rational arrangement and organization of one-day life in the kindergarten, as well as design and instruction of kindergarten activities, etc. and enable the students to make use of basic theories that they have learned about the preschool education to analyze and solve practical problems relative to the early childhood education and own a basic quality to engage in the early childhood education. The course goal emphasizes the cultivation of students' abilities of connecting theories with the practice and lays a foundation for the design and organization of all kinds of educational activities in kindergartens, highlighting the practicality of preschool education.

In order to make it easy to grasp the overall thinking of the course reform and achieve the course goals of pre-school education, we have adjusted and optimized the course contents and divided them into three parts. The first part introduces basic theories of the preschool pedagogy, including objects to study for the preschool pedagogy, early childhood education and social development, early childhood education and children's development; the contents given in this part are designed to help students establish a correct view of education, view of children and view of teachers, laying a preliminary theoretical foundation for the study of other parts; the second part shows goals, tasks and contents of overall development in moral, intelligence, physical education and aesthetics relative to the early childhood education, which are among major policies for kindergartens in the primary stage of the socialism in China and it indicates the direction for students to engage in the early childhood education in the future; the third part describes ways and methods to achieve the goals of kindergarten education, including environmental arrangement and use, cooperation between kindergartens and families or communities as well as kindergarten activities (such as teaching, games, one-day life), which are basic skills for students to master for work of care and education and also important parts for integrating theories to practices. Thus the optimization of course contents increases the practicality and pertinence of the teaching and highlights the practice of the preschool pedagogy courses.

\section{Strengthen the Practice Training AND Renovate TEACHING MODES}

In order to ensure the realization of teaching goals, it is a must to change traditional dull-teaching modes, following the principle of "student-centered and teacher guiding", we can adopt diverse teaching modes such as case teaching, simulation exercises, practical training, practice and more so as to form students' abilities in practice. 


\section{A. Case Teaching Enabling Students to Set up Scientific Concept in Education}

The concepts of a teacher in education determine what he will select as a goal, instructional contents and strategies during the education and also show his attitudes to children. It can be said that what the concepts he holds in education determines what he will do in education; as a result it will affect the results of education and the children's development. However, during the school-based teacher training, we find what teachers are in a great need are theories of modern education and what the teachers feel the most difficult is how to update the educational concepts. ${ }^{[2]}$ So during the course of teaching, we have always been placing the goal "insist on and adopt scientific educational concepts to solve problems concerning the early childhood education" on an important position and achieved better teaching results through case analysis and simulation exercises. After students have mastered basic theories and related analysis techniques, the teachers will display typical cases through pictures or characters according to the teaching goals and contents and then bring the students into specific scenarios to further improve their abilities of recognizing, analyzing and solving specific problems through independence thinking or collective collaboration. For example, "to have children esteemed" is an educational concept known for all students, yet it is not as easy as it is expressed in a specific scene with proper phases. A class case shows: Duoduo is a fat kid with an open personality, but many classmates often laugh at him, saying "Duoduo is so lazy and he could not even raise his hands in exercises", hearing of that Duoduo said angrily: "I am going to everywhere but not the kindergarten from tomorrow". A teacher whispered to him: "Duoduo, Why do you stop exercises?" "It is so difficult and out of my ability." Duoduo replied, from the case, problems can be raised from two aspects, (1) How to know what Duoduo felts at that moment; (2) What the teacher will do facing the criticism against Duoduo. In the opinion of the author, the teacher should instruct the students to consider what Duoduo felts being a child, based on which, a solution will be made for simulation exercises. Through such analysis and exercises, the abstracted concepts learned in the preschool pedagogy are embodied and shown in life and internalized into the educational concepts of students so to as provide instruction for their educational practice in the future.

\section{B. Practical Training to Form Students' Skills in Education}

In order to enable the preschool pedagogy to really promote the development of students and provide effective solutions for problems arising in education, it is a must to put the theories of early childhood education into the early childhood life and education practices. Only through this way can it lay a preliminary practice foundation for the students to engage in the early childhood education after graduation.

First, create scenarios for simulation exercises and make a targeted training of students in educational skills. The detailed operation is given as follows: Organize students at training rooms to practice constructive plays and make toys, etc; let students design and arrange a class environment for a kindergarten then arrange the students to simulate and organize performance games, intellectual games and the like. In addition, assume a scene according to the description of teachers, the students may be divided into groups for discussion and simulate dialogues in different educational scenarios from which students may learn skills for communications.

Second, increase the time for educational probation and internship so as to accumulate perceptual experience and training of educational skills. Within the first year of the preschool pedagogy program, following the teaching contents, we arrange a one-week internship for the students last semester. Before the end of the practice, teachers should give students methods for observation and records, requiring students to pay more attentions to and analyze the educational conducts of teachers and behaviors of children as well as the teacher-child interaction in one-day life. Through the on-the-spot observation, the students can fully understand the goals, contents and ways for the comprehensive development of education in kindergartens and learn skills to communicate with children and their parents. In the next semester, the we arranged a three-week nursery internship for the students, whose main activities include observing the organization of children's plays and teaching activities, teaching the children a regular game, participating in free activities, and creating scenarios. Through the zero distance contact with the children, the students may constantly find what they are interested in and form the knowledge and skills that they need which are integrated to the cognitive structure of their own through personalized ways so as to improve the knowledge structure they have formed. Undergoing the education and training exercises, the students can not only grasp the basic knowledge of education but also form skills in care and education and experience the feelings of being preschool teachers in practice so as to comprehensively enhance the practical value of the preschool pedagogy.

\section{VAlue Practical EVAluation AND InNOVATE EXAM METHODS}

Course evaluation plays an important role in the course design and implementation, owing functions of identification, diagnosis, improvement and orientation. ${ }^{[2]}$ According to characteristics of the course and the actual conditions for students to learn and develop, we may conduct a staged evaluation on the students and value the evaluation on the practice process through the combination of qualitative evaluation and quantitative evaluation, students' selfevaluation and students' mutual evaluation so as to make a great innovation on the exam methods of the preschool pedagogy.

\section{A. Arrange Students to Set Questions and Receive Closed- book Examinations in Order to Check What Students Have Leaned about Basic Knowledge}

The preschool pedagogy, one of the theoretical courses required for the preschool pedagogy specialty, requires students to understand and master the basic theoretical knowledge and take it as a guide for practical activities, so it is necessary to take written examinations to check what the students have leaned about the theoretical knowledge. 
Accordingly it needs to break the passive situation of students in examinations and promote their internalization of the knowledge. Detailed operation is given here: first of all, instruct the students to make a comprehensive review and put forward requirements for the scope of questions, coverage, type, focus and score distribution, then arrange 6-8 students to form a group for work division and cooperation, jointly discussing and drafting a test paper and answers which will be discussed among groups for reviews and learning by each other. At last after being modified by groups, it will be determined as an official test paper, copied as required and sent to groups in other the classes at the same level, and the text papers will be exchanged among groups for testing and marking. On the one hand, the students who draft the test paper shall mark it and assess the test results; on the other hand, the students who take the exams will take charge of analysis and evaluation and additional scores will be given to the group whose test paper is evaluated excellent.

\section{B. Check Students' Abilities in Linking Theory to Practice through Case Recording, Spot Check and Oral Tests}

Within the preschool pedagogy such contents as "principle for kindergarten education", "moral education", "kindergarten environment" and "early childhood games" and more are of higher practicability, requiring students to master certain basic theoretical knowledge and also apply what they have learned to solve problems in practice. Therefore facing such a opportunity of internship, students are arranged homework assessment, requiring two students as a group to record four cases and label targeted problems as per the cases and then write evaluation comments and submit the problems to teachers after modification and screening by groups. Finally, the teachers will organize students for oral tests via drawing lots; those who label the problems will take charge of evaluation to which the teachers will provide supervision and instruction. When distributing scores $50 \%$ of the results will be given to the problem labeling and oral testing respectively.

\section{Check Students' Basic Skills in Education through Group Cooperation and Practical Exercise}

After training in training rooms, internships and practices, the students have initially mastered basic skills as organization ad instruction in the creating of kindergarten scenarios, constructive plays and performances. After completion of the practical exercise at each stage, arrange 6-8 students as a group for check and the main contents include: create a theme constructive play and make an evaluation on the basis of overall thought, shape design, material operation and use, color distribution, applicability for children's characteristics and interests; organize the children to make a performance and mark on the basis of analysis on materials, scenario, character distribution and cooperative performance; design a theme activity area for a class at a given age, each students is required to make a toy with operating methods and educational functions shown, besides, it shall have a clear theme, able to operate and instruct, then take a group-based check. Create a cooperative atmosphere for students, foster their abilities in consciousness and cooperation and train their skills in education.

\section{CONCLUSION}

As far as the course evaluation, the teachers should not be taken as referees but motivators for students to learn and regulators in teaching, after participating in the teaching evaluation, the students shall rethink what they have learned and give views to teachers' teaching. This assessment method is in line with characteristics of the students, creating more appropriate opportunities for education and conditions and doing good to the comprehensive development of the students.

\section{REFERENCES}

[1] Li Jimei, Foundations for Early Childhood Education [M] Beijing: Beijing Normal University Publishing House, 1999:182-199.

[2] Zhan Daoxiang, Reasons and Countermeasures of Troubles in Teaching of Preschool Pedagogy [J]. Research on Early Childhood Education, 2005(11).

[3] Chen Xingjun, Preschool Pedagogy [M]. Beijing: People's Education Press, 2003:93. 